Vol. 4, No. 02; 2021

ISSN: 2581-4664

\title{
RESEARCH ON THE STATUS QUO AND IMPROVEMENT STRATEGIES OF COLLEGE STUDENTS' INFORMATION LITERACY IN AUTONOMOUS ORAL ENGLISH LEARNING UNDER THE BACKGROUND OF "INTERNET+"
}

\author{
Long $\mathrm{Wu}^{1}$, Haowei $\mathrm{Ti}^{2}$,Ding $\mathrm{Ma}^{3}$ and ${\mathrm{Zhi} \mathrm{Li}^{4}}^{4}$ \\ ${ }^{1}$ Information Department, Junyao Cooperation,No. 999, Jinzhou Road, Tuqiao, Jinniu District, Chengdu, Sichuan, \\ China \\ ${ }^{2}$ Acadmic Department, Hong Kong Asia Business College,21/F, Kie Qun Commercial Building, 38 Bi Street, Yau \\ Ma Tei, Kowloon, Hong Kong \\ ${ }^{3}$ Marketing department, Limkokwing University of Creative Technology,Inovasi 1-1, Jalan Teknokrat 1/1, 63000 \\ Cyberjaya, Selangor Darul Ehsan, Malaysia \\ ${ }^{4} \mathrm{PGC} /$ Infrastructure University Kuala Lumpur,MalaysiaUnipark Suria, Jalan Ikram-Uniten,43000 Kajang, Selangor \\ Darul Ehsan,Malaysia
}

http://doi.org/10.35409/IJBMER.2021.3235

\begin{abstract}
In today's global economic development, the exchanges between countries are becoming more frequent, and the requirements for foreign languages, especially English, the world language, are getting higher and higher. In business negotiations, international trade, and foreign cultural exchanges, English is an essential communication tool. In order to promote our country's foreign exchanges and cooperation, college students' English ability, especially the ability of spoken English, continues to improve. The society is now in an era of rapid development of scientific and technological information. The emergence and iterative update of the Internet has pushed people from the PC to the mobile. The mode of learning English has also developed from the most traditional physical teaching mode to online teaching. The mobile potential teaching model in the current situation. It promotes the diversification of teaching modes.
\end{abstract}

Keyword: English teaching mode; information literacy; autonomous learning; improvement strategies.

\section{INTRODUCTION}

The Internet itself contains rich content and broad coverage. It can provide college students with richer and diversified teaching resources, so that learning is no longer limited to a certain period of time or a certain place, but also can use Internet resources to customize a special learning plan suitable for them. Of course, there are pros and cons to any one thing. Although the "Internet +" environment makes the learning model no longer limited to the traditional model, there will still be various problems in it. This article elaborates on the current situation of college students' oral English learning under the environment of "Internet+", the problems that arise, and the solutions and improvement strategies. 


\section{International Journal of Business Management and Economic Review}

Vol. 4, No. 02; 2021

ISSN: 2581-4664

\subsection{The current situation of college students' autonomous learning of spoken English}

On July 4, 2015, the State Council of China issued the "Guiding Opinions of the State Council on Actively Promoting the "Internet +" Action", which opened the prelude to the "Internet +" era. Since that day, "Internet + " has become a new form of the Internet industry, and its structure has promoted new reforms and development in all walks of life ${ }^{[1]}$.

\subsection{Educational problems existing before the implementation of the "Internet + " model}

Since the implementation of the concept of "Internet + ", many industries have begun online development models, such as Internet + finance, Internet + logistics, Internet + trade, etc. everywhere. Among them, Internet + education is the most prominent and interesting industry.

In the past, the scarcity of educational resources and unequal distribution led to serious education tilt across the country ${ }^{[8]}$. In some places, students cannot get a good cultural education because of insufficient educational space and insufficient educational teachers, which makes the national quality of our country unable to significantly improve. The emergence of "Internet +" has solved the problem of insufficient quality and cultural education caused by the scarcity and uneven distribution of educational resources.

\subsection{Changes after the implementation of the "Internet + " model}

In the era of "Internet +", many educational resources are shared. This is equivalent to an online world university, where everyone can search for the information they need or are interested in for research and understanding ${ }^{[2]}$. Because of the fast update speed of the Internet, the speed at which people obtain information has increased, and the scope of knowledge has rapidly expanded. Many information that was previously limited by space or resources can now be obtained quickly. Among them, the popularity of English is thanks to the spread of "Internet+". Because of the existence of "Internet+", learning English is no longer limited to the explanation of the contents of the books in the classroom. Information sites on the Internet, English videos, audios, online course teaching and foreign social networking sites can all help college students greatly improve their English listening.English is a language that gathers foreign vocabulary. Its language database is updated every moment ${ }^{[9]}$. If it is just a book, it is impossible to update the vocabulary in the students' minds in time. The Internet can allow students to quickly remember and understand the meaning of new vocabulary through lively and interesting teaching methods, and store it in their own dictionaries.

\subsection{Survey on the use of APP in the "Internet +" environment}

There are many apps on the market for learning English, and many college students learn online by downloading apps and registering accounts ${ }^{[7]}$. The following is a sample survey of college students in Heilongjiang Province (from freshman to senior year and graduate students) to show the current use of mobile apps by college students. A total of 100 questionnaires were issued, among which 99 questionnaires were returned, with a recovery rate of $99 \%$, and a questionnaire effectiveness rate of $97 \%$, with high reliability. Figure 1 below is the data for whether college students can leave the app. 
International Journal of Business Management and Economic Review

Vol. 4, No. 02; 2021

ISSN: 2581-4664

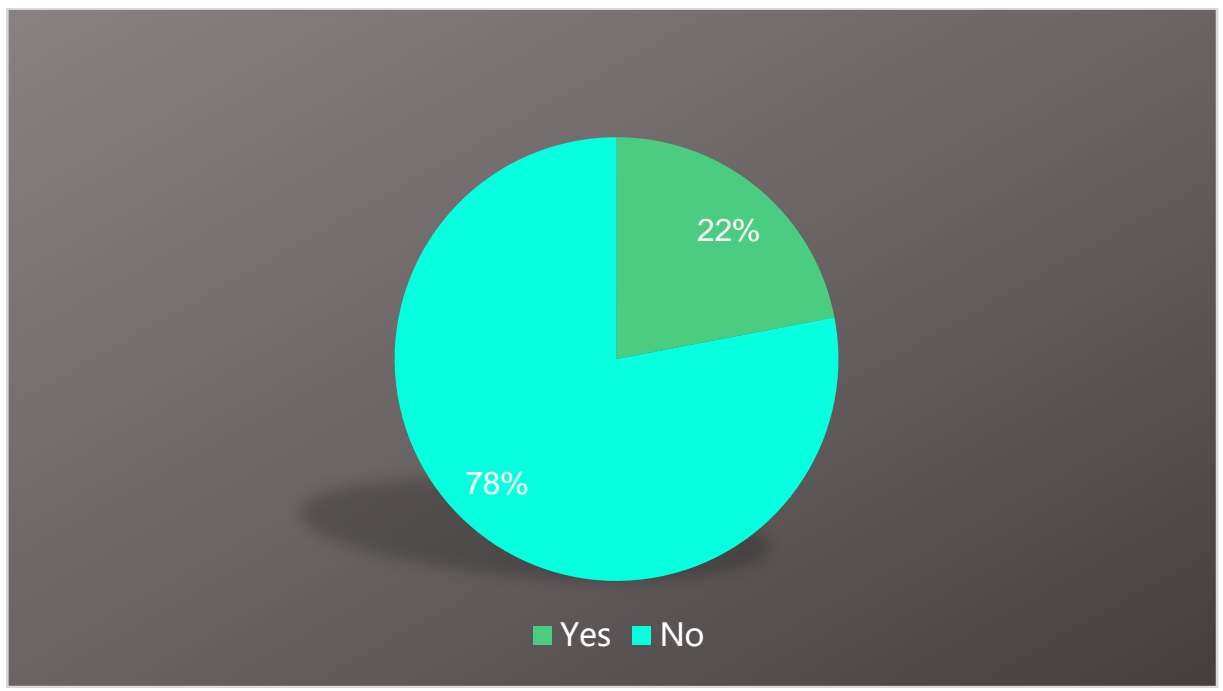

Figure. 1 Investigation on whether college students can leave the app

As shown in Figure 1,22\% of students can leave the app, while $78 \%$ of students cannot leave. This situation shows that most students have fully integrated into the era of "Internet + " and use the mobile Internet to study and live.Next, let's take a look at the proportion data of college students' apps for education and learning.

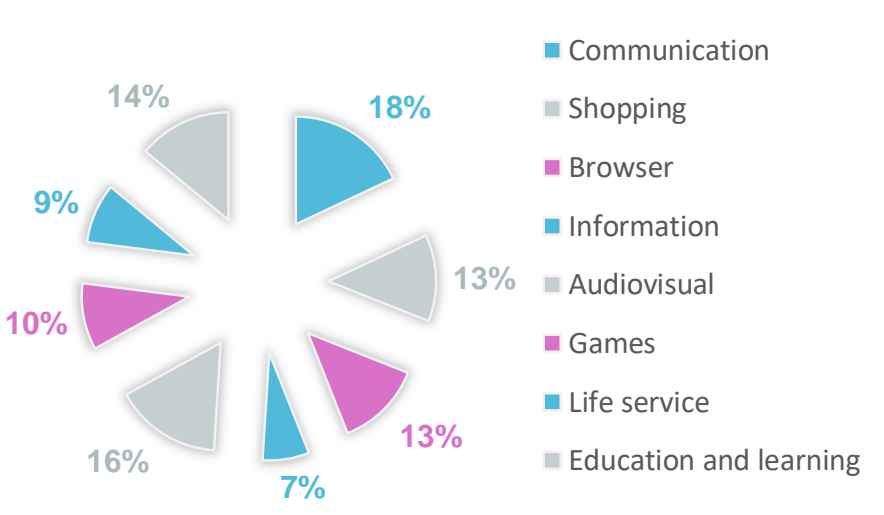

Figure 2 The use of apps by college students

As shown in Figure 2, we can see that the top three types of apps used by college students are communication, audio and video, and education and learning. It can be seen that there are still a lot of students using apps for online learning. Then we continue to conduct sample surveys 


\section{International Journal of Business Management and Economic Review}

Vol. 4, No. 02; 2021

ISSN: 2581-4664

among college students who use education and learning. This time, the sample object is expanded to 324 people, the scope of the object is concentrated in the undergraduates from freshman to senior, thenumber of people is shown in the following table:

Table 1 Number of users of English app learning software during university

\begin{tabular}{|l|l|}
\hline Grade & Number of users \\
\hline Freshman & 52 \\
\hline Sophomore & 95 \\
\hline Junior & 101 \\
\hline Senior & 76 \\
\hline
\end{tabular}

For these students, we asked whether to use the app for English learning. As a result, everyone gave a positive answer. The usage rate of English learning software is as high as 100\%. Next, we once again conducted a questionnaire survey with these students on "Which aspect of English learning using apps". The results showed that $45.99 \%$ of the students used to accumulate vocabulary and $58.02 \%$ of the students used the training of listening, reading and writing. , $74.07 \%$ of the students are used for exam preparation, $41.67 \%$ of the students are out of interest in English.

\section{THE ADVANTAGES OF "INTERNET +" LEARNING ENGLISH}

The entire Internet is equivalent to a world library, and all necessary teaching resources can be found on it. It perfectly solves the limitations of space and time under the traditional teaching mode. College students can replenish their knowledge anytime and anywhere, and can carry out autonomous learning of spoken English in a multi-modal way ${ }^{[6]}$. English is a language, and its charm needs to be demonstrated through communication. It is not enough just to know the knowledge in books. The improvement of oral English requires a lot of open practice, and it can be improved in dialogue with others. It is promoted by many factors such as current audio equipment, professional oral teachers, a good teaching environment, and a large number of oral practice opportunities to make oral English to a higher level.

Therefore, English learning is not only limited to books, movies, animation, music, and social interactions can be a good way to improve oral English. We can promote the improvement of learning ability by means of entertaining and entertaining, and use the timely update of the Internet to constantly refresh our knowledge repository, expand English vocabulary, become familiar with localized language expressions, and improve our oral expression skills.

It can be seen from the above that spoken English needs to be urged by various conditions and factors to grow rapidly, which reflects the necessity of "Internet + " for oral English learning. The Internet is a general trend for oral English learning. It makes spoken English more accessible, fragmented, and simplified. It allows college students to easily improve their oral English anytime and anywhere without being hindered by the environment or teaching resources ${ }^{[5]}$.

\section{PROBLEMS IN "INTERNET +" ENGLISH LEARNING}

Everything is two-sided, with pros and cons. Although the "Internet + " model provides a variety of ways for college students to learn spoken English independently, the disadvantages are 
International Journal of Business Management and Economic Review

Vol. 4, No. 02; 2021

ISSN: 2581-4664

still significant.

3.1 Investigation of the unevenness of various information and the reasons under the "Internet +" model

Many dross have also flooded into college students who are thirsty for learning following the Internet wave. In many mobile Internet products, there are many undesirable advertisements. , The quality and education level of some people on social tools are also uneven, which has laid a lot of hidden dangers for college students who are studying ${ }^{[4]}$.

The group of data in the following table is mainly for college students who have used the app and no longer apply it, or have never used it before. They have done a survey on why they gave up using the app for autonomous learning. The sample size is still 105, and the effective rate is $100 \%$

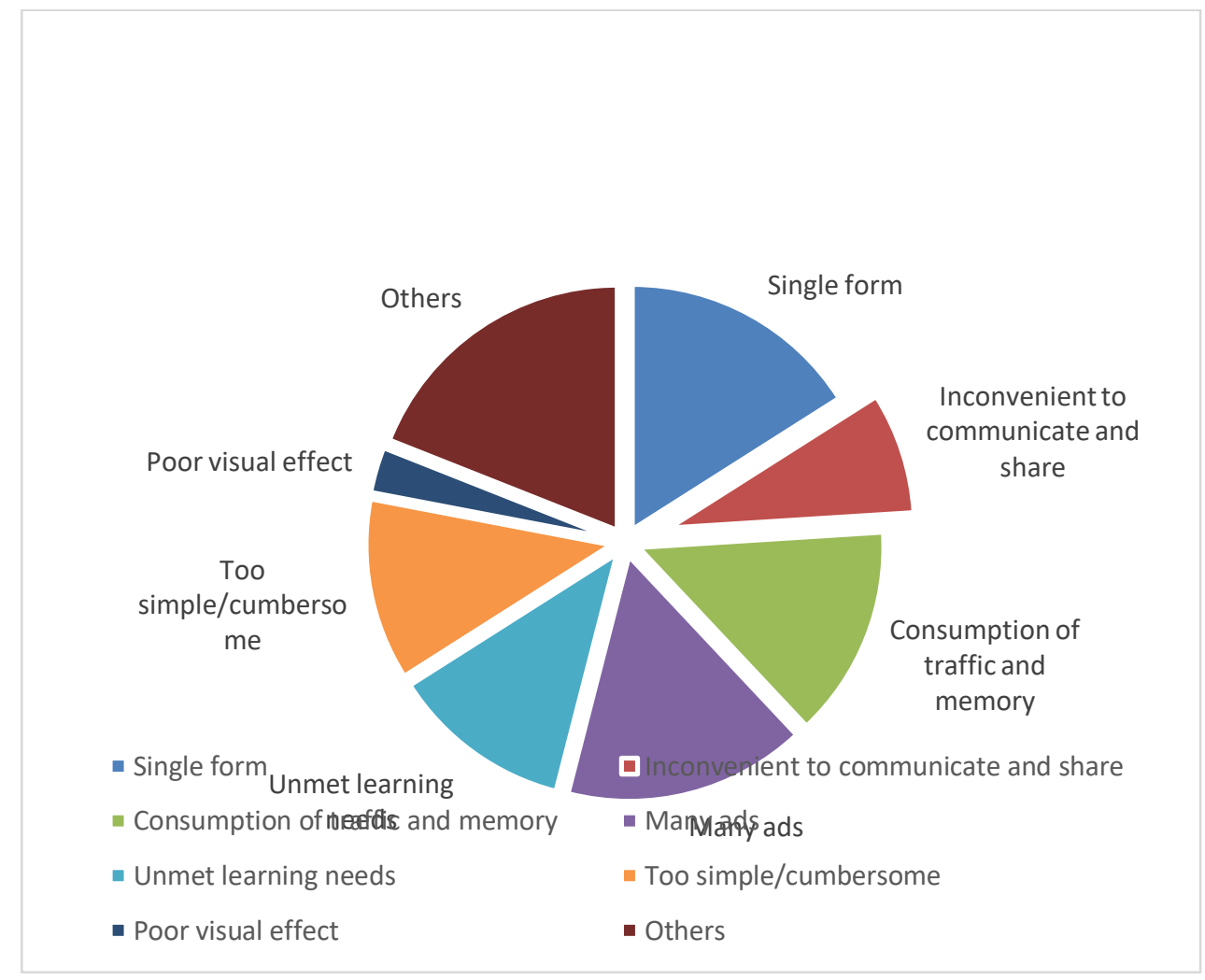

Figure 3 Reasons for rejecting app

It can be seen from the above image that the "Internet + " products are developing too fast. After achieving normal operation, the content is still slightly lacking. Excluding the reasons for other categories, the highest proportion is the single learning form. This also means that the compatibility of a single app is not high. Although the Internet has achieved a great integration of resource reserves, the mobile terminal has not yet been able to achieve resource compatibility; and there are too many advertisements, and it is precisely the previously mentioned redundant information that has not been screened, which affects the efficiency and experience of learning, 


\section{International Journal of Business Management and Economic Review}

Vol. 4, No. 02; 2021

ISSN: 2581-4664

and thus affects To improve college students' oral English ability ${ }^{[3]}$. The following problems consume traffic, occupy memory, cannot meet learning requirements, and content polarization. This can be attributed to two points: First, the content design is unreasonable, and second, hightech needs to be strengthened.

3.2 The usage rate and feedback survey of classified personnel of various English learning apps under the "Internet + " mode

What are the English learning apps on the market, what percentage of people use these apps, and what are the expectations of college students for English learning apps?

According to the statistics of 105 effective people, the usage of English learning app is shown in the following table:

Table 2 App usage survey

\begin{tabular}{|l|l|l|}
\hline App & Number of users & Proportion \\
\hline Youdao dictionary & 75 & $71.43 \%$ \\
\hline Kingsoft & 23 & $21.9 \%$ \\
\hline Baidu dictionary & 10 & $9.52 \%$ \\
\hline Scallop word & 36 & $34.29 \%$ \\
\hline Leci & 2 & $1.9 \%$ \\
\hline Hundred words & 49 & $46.67 \%$ \\
\hline Fluent in English & 3 & $2.86 \%$ \\
\hline Lazy English & 1 & $0.95 \%$ \\
\hline Crazy English & 3 & $2.86 \%$ \\
\hline Hujiang English & 11 & $10.48 \%$ \\
\hline New concept English & 4 & $3.81 \%$ \\
\hline Langyi English & 3 & $2.86 \%$ \\
\hline VOA & 13 & $12.38 \%$ \\
\hline Others & 17 & $16.19 \%$ \\
\hline
\end{tabular}

It can be seen from the above table that the main form of the English learning app is indeed too singular. The highest proportion is the word vocabulary, and the proportion for listening, speaking, reading and writing is too low. ${ }^{[9]}$ Speaking fluently in English, these spoken-based apps account for less than 3\%. In line with the feedback in the above picture, the learning form is single.

Table 3 App improvement direction, number and proportion

\begin{tabular}{|l|l|l|}
\hline $\begin{array}{l}\text { Expected features of } \\
\text { English app }\end{array}$ & Number of users & Proportion \\
\hline Accurate instruction & 85 & $80.95 \%$ \\
\hline
\end{tabular}




\section{International Journal of Business Management and Economic Review}

Vol. 4, No. 02; 2021

ISSN: 2581-4664

\begin{tabular}{|l|l|l|}
\hline \hline content & & \\
\hline Rich in content & 63 & $60 \%$ \\
\hline $\begin{array}{l}\text { No ads, low traffic } \\
\text { consumption }\end{array}$ & 73 & $69.52 \%$ \\
\hline $\begin{array}{l}\text { Beautiful UI and simple } \\
\text { operation }\end{array}$ & 60 & $57.14 \%$ \\
\hline $\begin{array}{l}\text { Good communication } \\
\text { experience }\end{array}$ & 32 & $30.48 \%$ \\
\hline Others & 12 & $11.43 \%$ \\
\hline
\end{tabular}

As can be seen from the above table, when college students use the English learning app, they most hope to improve, and they can also indirectly see some problems in the English app.

\subsection{Summary based on the survey data of English APP under the "Internet+" mode}

To sum up, the problems in the process of autonomous English learning for college students under the English learning app or "Internet +" mode are as follows.

1. The learning content is monotonous and the form is single, which is not enough to meet the diverse needs of college students;

2. App function guidance is not detailed and fails to accurately guide college students to use the app. The content is not precise enough and lacks calibration;

3. Too much advertising intervention and too strong commercial nature affect the learning experience of college students;

Fourth, the technology needs to be improved, and the consumption of data is always a big problem for college students;

5. The interface structure design and operation design need to be optimized to solve the problem of inconvenience to use the app;

6. The English learning app enhances social functions and provides better channels and platforms for oral training; ${ }^{[11]}$

4. UNDER THE BACKGROUND OF "INTERNET+", THE STRATEGIES FOR IMPROVING COLLEGE STUDENTS' AUTONOMOUS LEARNING OF SPOKEN ENGLISH

Aiming at the problems of college students' autonomous learning of spoken English in the context of the above "Internet $+"$, this article proposes the following strategies: 
Vol. 4, No. 02; 2021

Figure 4 Strategies for improving college students' autonomous learning of spoken English

\subsection{Enriching learning content and expanding learning forms}

The Internet platform expands the learning content section of the mobile app, do not make a separate module. The platform can effectively integrate word expansion, oral communication, and social communication to create a rich, multi-level oral teaching and training environment to meet the diverse needs of college students for oral learning ${ }^{[10]}$.

\subsection{Content calibration and compiling detailed function instruction manual}

The Internet platform ensures that the content of the app is accurate and authoritative, reduces misleading misinformation, and writes the function manual as detailed as possible to guide the college students to operate more accurately.

\subsection{Blocking redundant ads}

Commercial advertisements on Internet platforms need to be screened to prevent the pop-up of undesirable advertisements, and limit the number and time of advertisements to create a relatively pure learning environment ${ }^{[12]}$. 
International Journal of Business Management and Economic Review

Vol. 4, No. 02; 2021

ISSN: 2581-4664

\subsection{Technological improvement, reducing traffic consumption}

The Internet platform can improve the technology, compress the package body, and optimize the code to meet the needs of traffic reduction and smooth operation, and create a stable mobile Internet learning environment for students.

\subsection{UI interface structure optimization and function optimization}

The Internet platform optimizes the UI interface and operation design according to user habits, and enhances social functions to provide a good spoken language training platform.

\section{CONCLUSION}

With the development of information technology, Internet + education has become an inevitable trend, and online teaching and mobile teaching have become the norm. Learning spoken English is no longer limited to a specific place, a specific occasion, or a specific time, and can be improved anytime, anywhere. This is a great good thing for college students. The Internet has provided them with favorable platforms and channels, and given them sufficient teaching resources, which also makes higher demands on the autonomous learning ability of college students. The learning model in the context of "Internet + " is a multi-modal and multipossible learning model. It has changed the status quo of college English learning. This change is extremely beneficial to our country's education and development. This not only spurred the formation of a new model, but also pushed contemporary college students onto a new development path, and this path directly introduced us into another brand new era.

\section{REFERENCE}

[1] Cui Yujue. Towards multiple co-governance: "Internet + classroom" teaching reform [J] Primary and Secondary School Management, 2016 (7)

[2] Zhao Jianhua. Comparative analysis of components of collaborative learning in classroom and web environment [J]. China Audio-visual Education, 2007 (2)

[3] Su Xiaobing, Guan Yuqi, Qian Dongming. Analysis of the concept of micro-class and its teaching application research [J]. China Audio-visual Education, 2014, (7)

[4] Zhang Maocong, Qin Nan, Internet + Education: Connotation, Problems and Model Construction [J]. Contemporary Education and Culture, 2016 (3)

[5] Chen Yun. Probe into the Mixed Teaching Mode of Colleges and Universities in the "Internet +" Era [J] Journal of Jiamusi Vocational College, 2016, (4)

[6] Li Zhuanggao. "Welcoming the Professional Development of Teachers in the" Internet + "Era", "Information Technology Education in Primary and Middle Schools", No. 10, 2015: 8-10

[7] Zhou Yangen, Sang Qingsong: "Discussion on the Research of Independent Learning Theory at Home and Abroad", Journal of Anhui Education College, 2016, Issue 1: 100-102

[8] Wang Shouren, Wang Haixiao: "Survey of the Status of College English Teaching in China's Colleges and Universities and the Reform and Development Direction of College English Teaching", "Chinese Foreign Languages" 2011 No. 5: 6-13

[9] Liu Dandan, Dong Cambridge, Li Xuening, "Construction and Management of the 
International Journal of Business Management and Economic Review

Vol. 4, No. 02; 2021

ISSN: 2581-4664

Ubiquitous Learning Environment in College English", "Chinese Journal of Education" 2013, Issue 10: 78-79

[10] Ma Wulin, Hu Jiasheng: "Impact and Reconstruction of International MOOCs on Chinese College English Curriculum", "Electronic Teaching of Foreign Languages" 2014, Issue 3: 50-56 [11] Zhang Yan, Critical Discourse Analysis of Chinese and American English News Discourses-Taking the Report of the Missing Flight of Malaysia Airlines Flight MH370 as an Example [J]. Journal of Qiqihar University (Philosophy and Social Sciences Edition), 2016 (10): $153-156$

[12] Shang Xuenan, Critical Discourse Analysis of English News Discourse from the Transitivity Perspective - Taking the "Indian Times" Report on the "Belt and Road" as an Example [J] Journal of Henan Institute of Engineering (Social Science Edition) 2017, 32 (4): 65 69 